\title{
The Epidemiology of Bone Metastases in Malignant Diseases
}

\author{
Mahmut GÜMÜş
}

Department of Medical Oncology, Istanbul Medeniyet University Faculty of Medicine, İstanbul-Turkey

\section{Introduction}

Cancer is a serious health problem leading to death most frequently after cardiovascular diseases. Due to the advancements in the diagnosis and treatment, survival in malignant diseases has improved considerably; today, cancer is considered to be a treatable and controllable chronic disease. Despite these favorable advancements, cancer patients develop metastasis, which has a lifetime negative effect on the quality of life.

The preliminary data on the frequency of bone metastasis development was obtained from postmortem studies. According to the data, bone metastasis frequency was $73 \%$ in breast cancer, $68 \%$ in prostate cancer, $42 \%$ in thyroid cancer, $35 \%$ in renal cell carcinoma, $36 \%$ in lung cancer, and $5 \%$ in gastrointestinal cancer. [1,2]

The malignant diseases most commonly causing bone metastases are breast cancer in women, and prostate and lung cancer in men. These are followed by renal cell tumors and malignant melanoma. In a study performed using electronic health records of patients, the 10-year bone metastasis incidence was $29.2 \%$ in prostate cancer, $8.1 \%$ in breast cancer, $12.9 \%$ in lung cancer, $9.9 \%$ in renal cell carcinoma, and 3.0\% in malignant melanoma. When the occurrences of all the cancers were combined, the rate was $8.4 \%$. In the same study, the 10-year bone metastasis incidence at the metastatic stage was found to be increased to $70.7 \%$ in prostate cancer, $61.4 \%$ in breast cancer, $26.2 \%$ in both lung cancer and renal cell carcinoma, and $10.4 \%$ in malignant melanoma; the combined rates of all the cancers was $27.6 \%$ (Fig. 1).[3]

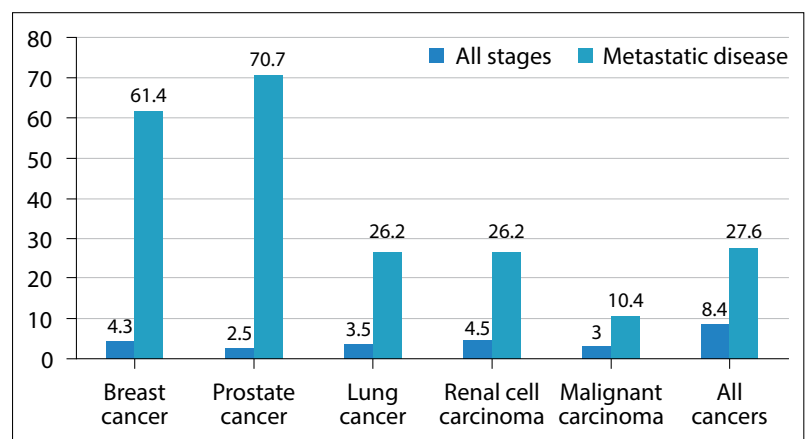

Fig. 1. The incidence of bone metastases over 10 years (\%) at all stages and the metastatic disease.

The frequency of bone metastasis at the first diagnosis was the highest for small-cell lung cancer followed by non-small cell lung cancer, renal cell carcinoma, prostate cancer, and breast cancer. The frequency of bone metastasis at the metastatic stage, as stated above, was found to be the highest for prostate cancer, followed by breast, lung, and renal cell cancers.[4]

When data outside of the United States was considered, studies from the United Kingdom, Denmark, and Canada did not show notable differences in the incidence of bone metastases among similar disease groups.[5-8]

When the relationship of bone metastases with age was considered, median age was found to be 65 years in patients with bone metastases. On the other hand, the median age was 72 in prostate cancer patients and 62 in breast cancer patients. This difference was considered to be related to the median age of onset of primary disease.[3] 
In general, the rates of bone metastases in the studies from Turkey were found to be between 9.9\% and $27.5 \%$.

Unlike western countries, the frequency ranks were $27.5 \%, 24.5 \%$, and $4.5 \%$ for lung, breast, and prostate cancers, respectively. The difference was probably caused by the inter-country difference in the incidence of these cancers. While prostate cancer ranks first in Western countries, lung cancer ranks first in our country. The median age for bone metastasis development was found to be 57 years, which was probably associated with the lower age of cancer diagnosis in Turkey.[9]

Previous studies from our country had found that the incidence of bone metastasis development was similar to lung cancer (28.4-39.0\%), breast cancer (14.3$25.5 \%)$, prostate cancer (11.0-14.5\%), and gastric cancer (3.8\%).[10-13] When the correlation between sex and bone metastasis was analyzed, it was found that bone metastases are more common in men. This might be because cancers with frequent bone metastasis development, such as prostate and lung cancer, are more common in males.[14]

Skeletal-related events constitute the morbidity of bone metastases. Pathological fractures, radiotherapy for bone metastases, surgical approaches for bone metastases, and spinal cord compression are defined as skeletal-related events. In a study on this subject, the 24-month cumulative incidence of the development of skeletal-related events was found to be $54.2 \%, 47.7 \%$, and $41.9 \%$ in breast, lung, and prostate cancers, respectively.[15]

Additional morbidities (pain, movement restriction, etc.) caused by the development of bone metastases and skeletal-related events have indirect negative effects on survival, with considerable negative effects on the quality of life. The survival periods after bone metastasis development were found to be 19-25 months in breast cancer, 12-53 months in prostate cancer, 6-7 months in lung cancer, 6-12 months in other urological cancers, and 6 months in malignant melanoma.[16]

Bone metastases usually cause skeletal-related events in the early stages of advanced diseases and negatively affect the quality of life. Skeletal-related events pose an additional burden on patients with different problems at the metastatic stage (Fig. 2).[17-21]

Thus, the determination of the risk of bone metastasis development in cancer patients, identifying the problems, and performing necessary treatment will help us combat cancer and improve the quality of life.

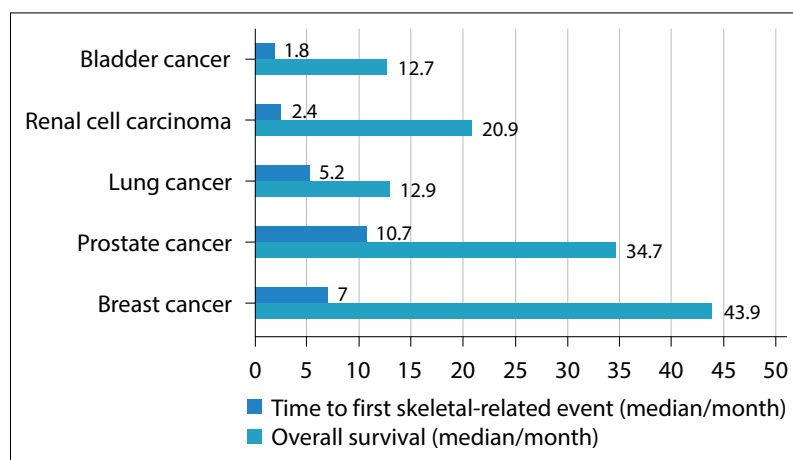

Fig. 2. The correlation between the first occurrence of skeletal-related events and overall survival.

\section{References}

1. Coleman RE. Clinical features of metastatic bone disease and risk of skeletal morbidity. Clin Cancer Res 2006;12(20 Pt 2):6243s-9s.

2. Galasko C. The anatomy and pathways of skeletal metastases. In: Weiss L, Gilbert A, editors. Bone metastases. Boston: GK Hall; 1981. p. 49-63.

3. Hernandez RK, Wade SW, Reich A, Pirolli M, Liede A, Lyman GH. Incidence of bone metastases in patients with solid tumors: analysis of oncology electronic medical records in the United States. BMC Cancer 2018;18(1):44.

4. Jiang W, Rixiati Y, Zhao B, Li Y, Tang C, Liu J. Incidence, prevalence, and outcomes of systemic malignancy with bone metastases. J Orthop Surg (Hong Kong) 2020;28(2):2309499020915989.

5. Hagberg KW, Taylor A, Hernandez RK, Jick S. Incidence of bone metastases in breast cancer patients in the United Kingdom: results of a multi-database linkage study using the general practice research database. Cancer Epidemiol 2013;37(3):240-6.

6. Jensen AO, Jacobsen JB, Norgaard M, Yong M, Fryzek JP, Sorensen HT. Incidence of bone metastases and skeletal-related events in breast cancer patients: a population-based cohort study in Denmark. BMC Cancer 2011;11:29.

7. Yerushalmi R, Woods R, Kennecke H, Speers C, Knowling M, Gelmon K. Patterns of relapse in breast cancer: changes over time. Breast Cancer Res Treat 2010;120(3):753-9.

8. Cetin K, Christiansen CF, Jacobsen JB, Norgaard $\mathrm{M}$, Sorensen HT. Bone metastasis, skeletal-related events, and mortality in lung cancer patients: a Danish population-based cohort study. Lung Cancer 2014;86(2):247-54.

9. Ulucaköy C, Yapar A, Şeyhoğlu MC, Tokgöz MA, Atalay İB, Güngör BŞ. Demographic features of metastatic 
bone tumors. Acta Oncol Tur 2021;54(1): 98-102.

10. Turkoz FP, Solak M, Kilickap S, Ulas A, Esbah O, Oksuzoglu B, et al. Bone metastasis from gastric cancer: the incidence, clinicopathological features, and influence on survival. J Gastric Cancer 2014;14(3):164-72.

11.Zengel B, Yararbas U, Duran A, Uslu A, Eliyatkın N, Demirkıran MA, Cengiz F, et al. Comparison of the clinicopathological features of invasive ductal, invasive lobular, and mixed (invasive ductal+invasive lobular) carcinoma of the breast. Breast Cancer 2015;22(4):374-81.

12. Sen E, Kaya A, Erol S, Savas I, Gonullu U. Kadınlarda akciğer kanseri: Klinik özellikler ve sağkalıma etkili faktörler [Lung cancer in women: clinical features and factors related to survival]. Tuberk Toraks 2008;56(3):266-74.

13. Yücel B, Celasun MG, Öztoprak B, Hasbek Z, Bahar S, Kaçan T, et al. The negative prognostic impact of bone metastasis with a tumor mass. Clinics (Sao Paulo) 2015;70(8):535-40.

14. Herget G, Saravi B, Schwarzkopf E, Wigand M, Südkamp N, Schmal H, et al. Clinicopathologic characteristics, metastasis-free survival, and skeletal-related events in 628 patients with skeletal metastases in a tertiary orthopedic and trauma center. World J Surg Oncol 2021;19(1):62.

15. Oster G, Lamerato L, Glass AG, Richert-Boe KE, Lopez A, Chung K, et al. Natural history of skeletalrelated events in patients with breast, lung, or prostate cancer and metastases to bone: a 15-year study in two large US health systems. Support Care Cancer 2013;21(12):3279-86.
16. Selvaggi G, Scagliotti G. Management of bone metastases incancer: a review. Clin Rev Oncol Hematol 2005;56:365-78.

17. Saad F, Gleason DM, Murray R, Tchekmedyian S, Venner P, Lacombe L, et al. Long-term efficacy of zoledronic acid for the prevention of skeletal complications in patients with metastatic hormone-refractory prostate cancer. J Natl Cancer Inst 2004;96(11):87982.

18. Saad F, Lipton A. Zoledronic acid is effective in preventing and delaying skeletal events in patients with bone metastases secondary to genitourinary cancers. BJU Int 2005;96:964-9.

19.Zaghloul MS, Boutrus R, El-Hossieny H, Kader YA, El-Attar I, Nazmy M. A prospective, randomized, placebo-controlled trial of zoledronic acid in bony metastatic bladder cancer. Int J Clin Oncol 2010;15(4):382-9.

20. Rosen LS, Gordon D, Tchekmedyian NS, Yanagihara R, Hirsh V, Krzakowski M, et al. Long-term efficacy and safety of zoledronic acid in the treatment of skeletal metastases in patients with nonsmall cell lung carcinoma and other solid tumors: a randomized, Phase III, double-blind, placebo-controlled trial. Cancer 2004;100(12):2613-21.

21.Lipton A, Theriault RL, Hortobagyi GN, Simeone J, Knight $\mathrm{RD}$, Mellars $\mathrm{K}$, et al. Pamidronate prevents skeletal complications and is effective palliative treatment in women with breast carcinoma and osteolytic bone metastases: long term follow-up of two randomized, placebo-controlled trials. Cancer 2000;88(5):1082-90. 